\title{
Design, Development and Geometric Error Analysis of an Aerostatic Rotary Table
}

Verílton Nunes da Silva, Luiz Henrique Melo Silva Nóbrega, Fábio de Andrade Barroso, Rafael Franklin Alves Silva, Jobson Francisco da Silva, José Carlos de Lima Júnior and João Bosco de Aquino Silva

Centro de Tecnologia, Universidade Federal da Paraíba-UFPB, João Pessoa 58059-900, Brazil

\begin{abstract}
Rotary tables are equipments in precision machinery applied in five-axis Machine Tools and CMM (Coordinate Measuring Machines), offering rotational (C-axis) and tilting motion (A-axis), allowing the obtaining of several configurations for manufacturing or inspection of parts with complex geometries. The demand for high accuracy, high efficiency and fewer errors in the positioning of the part in precision machines increases every day, thus ensuring their high confidence and the use of aerostatic bearings enable constructive innovations to the equipment. In this context, this work presents the mechanical design, the development and error analysis of a prototype of an aerostatic rotary table. This study emphasizes the analysis of a prototype that uses the air as a working principle for reducing friction between moving parts, increasing the mechanical efficiency, and its influence of motion error is also discussed based on the experimental results. For the geometrical errors analysis, experimental tests were realized in laboratory using a DBB (Double Ballbar). The tests are performed with only one axis moving, observing the behavior of the system for different feedrate at the $C$-axis.
\end{abstract}

Key words: Rotary tables, aerostatic bearings, double ballbar, geometric errors, coordinate measuring machines.

\section{Introduction}

The need for components with high dimensional accuracy and surface quality has encouraged many researchers around the world to focus on the development of measurement of machine tools and instruments to achieve the desired levels of accuracy [1]. The increasing need for manufacturing and measuring parts of complex geometries with high accuracy, five-axis machines are used in various applications requiring high accuracy [2].

Machines with multiple axes are usually composed of three axes performing linear motions and two rotational movements, these known as rotary tables. The rotary tables incorporate high precision and good stiffness in machine tools and CMM (Coordinate Measuring Machines). In general, one of the axes is used to rotate ( $C$-axis) and the other to tilt ( $A$-axis) the piece to be machined or measured by significantly

Corresponding author: Verílton Nunes da Silva, Ph.D., research field: design, development and error analysis of an aerostatic rotary table, and precision engineering. increasing tool access or the probe to provide a substantial gain time material removal or inspection by the probe.

With the assistance of these rotary tables, several advantages were provided to the manufacturing industry, such as the significant reduction of set-up time of a machine, better accessibility tool and more flexibility during the machining operations [3].

The constructive forms of a machine tool or measuring machine are related to the measurement volume, measurement uncertainties, the technology used by manufacturers and others. Constructive factors, such as aerostatic bearings to replace the recirculating ball guides, allow manufacturers to decrease the machine level of uncertainty [4].

The use of aerostatic bearings in engineering design provided a significant increase in mechanical efficiency due to reduced friction between components that perform movement, and became elements in search of greater accuracy, stability and high performance to high rotation [5]. All this thanks 
to a thin film at high air pressure that can bear the load between the moving surfaces, that is, the film thickness characterized the bearing stiffness [6].

The rotary tables, besides the advantages presented, also have disadvantages, such as for errors that arise during assembly and operation of the machine. The prerequisite for the proper design of a machine is the measurement and identification of the origin of errors, which depend on the measuring instrument and the error identification techniques.

The accuracy of the results obtained by a rotary table is linked to several factors, quote: the mechanical precision of the machine; the drive system of the machine; the data acquisition system; the accuracy of the machine control system; the machining strategy or measurement of the piece; the fixing of the piece and its mechanical properties [3].

Based on the above, this work presents the mechanical design, the development and error analysis of a prototype of an aerostatic rotary table, using the ballbar system for measure geometric errors inherent of the rotary table. This study had emphasis at the analysis of a prototype that uses the air as a working principle for reducing friction among the moving parts, increasing the mechanical efficiency, and the influence of motion error is also discussed based on the experimental results.

It is noteworthy that there are currently high accuracy machines that already use aerostatic bearings in rotary tables, but the manufacturers do not provide information about the design details, as well as parameters that can be used as a reference for a new project. This work aims to find design parameters to improve the accuracy of a precision machine.

\section{Rotary Tables: Overview}

Many studies include the use of ballbar as a measuring instrument for identify geometrical errors on rotary tables. Khan and Chen [7] created a methodology that was developed and implemented for the characterization, evaluation and quantification of errors in rotary joints of five-axis machine tools using the Ballbar system.

Zhu et al. [8] present an integrated method for modeling, identification and compensation of geometric errors in machine tools, and the ballbar was used to identify six errors due rotary tables.

Lee and Yang [9] evaluated the accuracy of a machine tool through a spherical deviation model based on measurements using the ballbar in the measurement planes XY, YZ and ZX, and [10] also presented a study of PIGE (position independent geometric error), including offset errors and squareness on rotary axes of five-axis machine tools, using the ballbar in measurements and checking through numerical compensation.

Lei et al. [11] present a new method that uses the double ballbar to inspect motion errors of the rotary axes of five-axis $\mathrm{CNC}$ machines tools. It was observed that when $\mathrm{CNC}$ machine tools are used for high feedrate contourning, whereby two or more axes are driven simultaneously, significant feedrate-dependent motion errors appear.

Tsutsumi [12] described a calibration methodology in five-axis machines, with two rotary axes, using the ballbar, and proposed a method of correction of deviations to achieve higher accuracy. Zhang et al. [13] proposed a method of geometric error detection measurement, using the ballbar and an approach developed to give assistance in the measurements on rotary tables of five-axis machine tools. Chen et al. [14] shows in his research an identification model of geometric errors based on the homogeneous matrix, using measurements with the Ballbar system in a machining center with four-axis, in order to decrease the influence of the inaccuracy of the measured parameters.

\section{Inherent Geometric Error in Rotary Tables}

Ideally, a body rotates about own axis without any errors. However, in reality the rotation links or joints also generate angular and translational errors which 
depend upon the axis of rotation [15].

In general, the rotary table includes the index error, wobble error and eccentricity. But conventional rotary table calibration techniques (laser interferometer or autocollimator) only calibrate the index error and the wobble error. Through the complete rotary table calibration, the errors of rotary table can be compensated [16]. The errors of rotary table with one axis were defined by 6 DOF, i.e. three linear positions errors, and three angular position errors, for each rotary table axis.

Fig. 1 shows the geometric errors inherent a rotary axes, where can provide rotation motion (C-axis) or tilt motion (A-axis).

According the figure above, considering the reference axis the coordinate center $\left(O-X_{1} Y_{1} Z_{1}\right)$, there are the following deviations:

- Linear errors: two radial, or eccentricity, errors $(\Delta x$ and $\Delta y)$ and an axial error $(\Delta z)$;

- Angular errors: two tilt, or wobble, errors ( $\alpha$ and $\beta$ ) and a rotation deviation $(\gamma)$.

Geometric errors are the most important errors in precision machines, because they affect the positioning accuracy during operation of the system. Geometric errors in high accuracy machines are caused by many factors, such as kinematic errors, termo-mechanical errors, loads and load variations, dynamics forces, and motion control and control software [19].

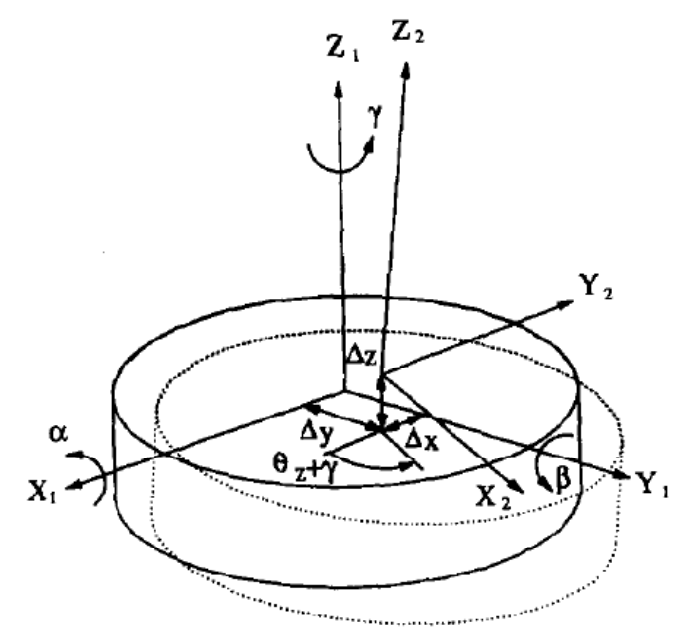

Fig. 1 Geometric errors inherent a rotary axes [15, 17, 18].
Geometric errors are categorized as PDGE (position-dependent geometric error) and PIGE. Here, "position" refers to the command for a controlled axis. PDGEs are caused mainly by imperfections in components, and PIGEs are caused mainly during the assembly process [20].

\section{Tests for Identification of Geometric Errors}

\subsection{Ballbar (DBB)}

The DBB is a tool used in the diagnosis of geometric errors in high accuracy machines, showing the actual conditions of the machine and instructing the operator in a possible intervention. The ballbar system is usually used for measurements of circular interpolation motion of two linear axes.

With the use of this equipment, it can be identified the following errors: circular and radial deviations, squareness, hysteresis, circularity, peak reversal, lateral play, scale error, straightness, among others.

Fig. 2 shows a schematic drawing of the basic components that forming the ballbar measurement system.

The DBB is a precision instrument used to measure relative displacement between the spindle and the table of a machine, by two precision spheres, which one remains fixed on the machine spindle and the other, the measuring sphere, will move during the tests.

For each DBB sphere there is a support for your fitting, where one of these supports is installed on the machine spindle (tool holder) and the other is set on the table (pivot assembly). Then, a telescoping linear sensor with extremely high accuracy connects the two spheres (Ballbar Assembly) and is installed collecting information regarding the distance of displacement while the machine follows a circular path programmed. The signals obtained are sent to a remote computer where and it will be processed via software.

The spindle of the machine is moved by three linear axes, $\mathrm{X}, \mathrm{Y}$, and $\mathrm{Z}$, to drive the ballbar rotating around the center point of the ball bawl of the socket installed 


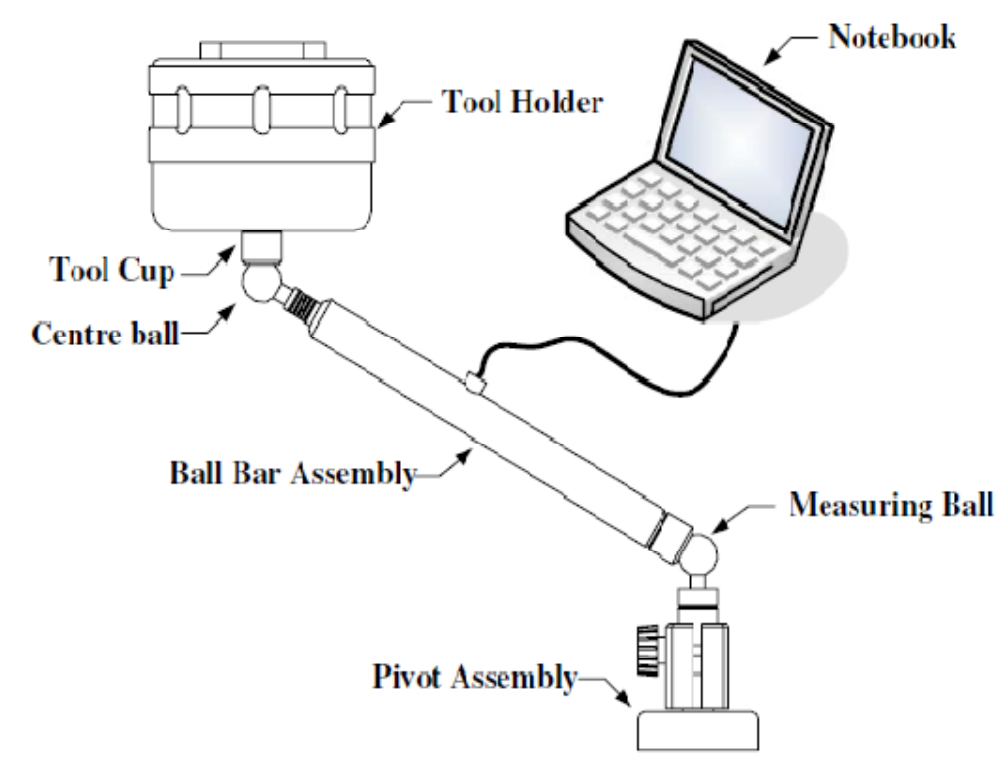

Fig. 2 Structure of DBB system [11].

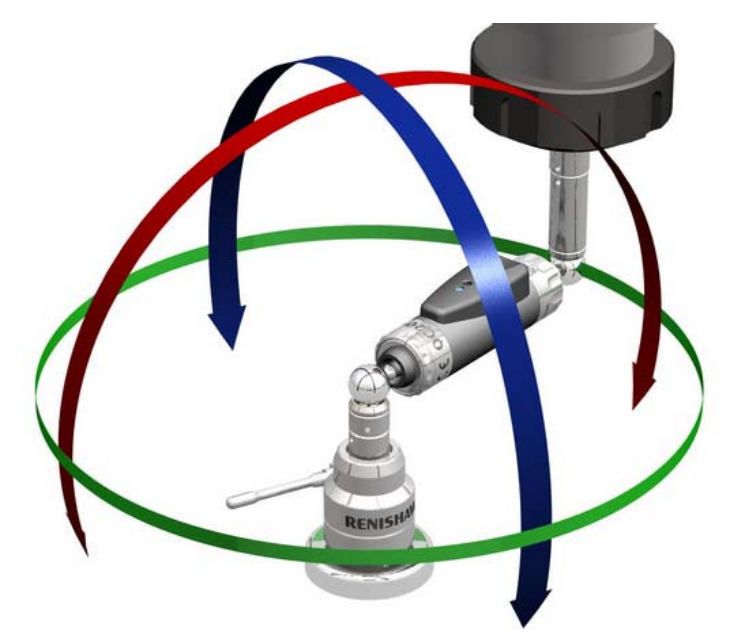

Fig. 3 Test scheme with DBB [21].

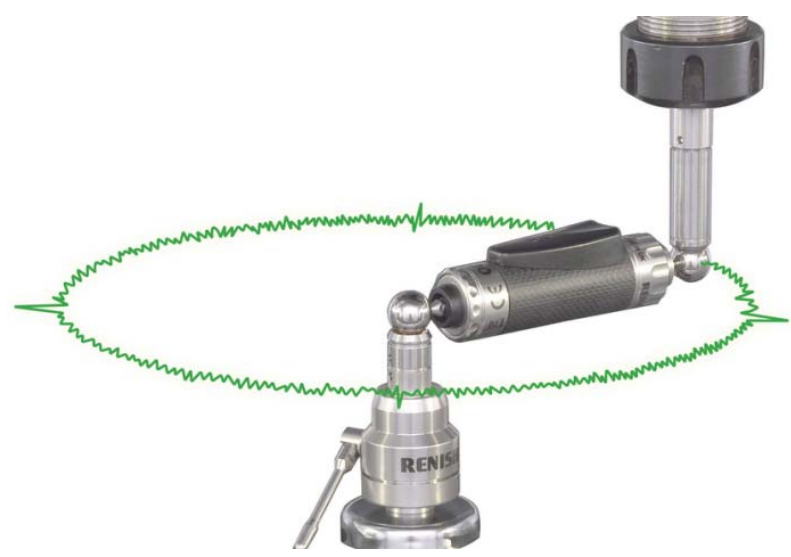

Fig. 4 Errors profile using a DBB [21].

on the workbench. Because the geometric errors of the machine tool are unavoidable, the sockets on the workbench and spindle deviate from their ideal position, and hence the position of the center are changed accordingly [14].

Fig. 3 shows a scheme of a test with DBB, emphasizing the possible data collection directions, where the movement is performed by the spindle of the machine tool or CMM.

Fig. 4 shows the errors profile measured by the measuring instrument in a work plane of a machine tool or CMM.

The main advantage of the DBB test method is that it can find a servo mismatch of the simultaneously driven axes, while the laser interferometer and other optical displacement measuring devices only find positioning errors of a single axis [11].

\subsection{R-Test}

In order to offer a possibility for the fast evaluation of a volumetric performance of five-axis machine tools, in one set-up and also for the determination of their geometrical parameters used in the numerical control, the $R$-Test has been developed. It also has the purpose of determining the geometric parameters using numerical control [22].

Fig. 5 describes the R-test device used in a several studies. 


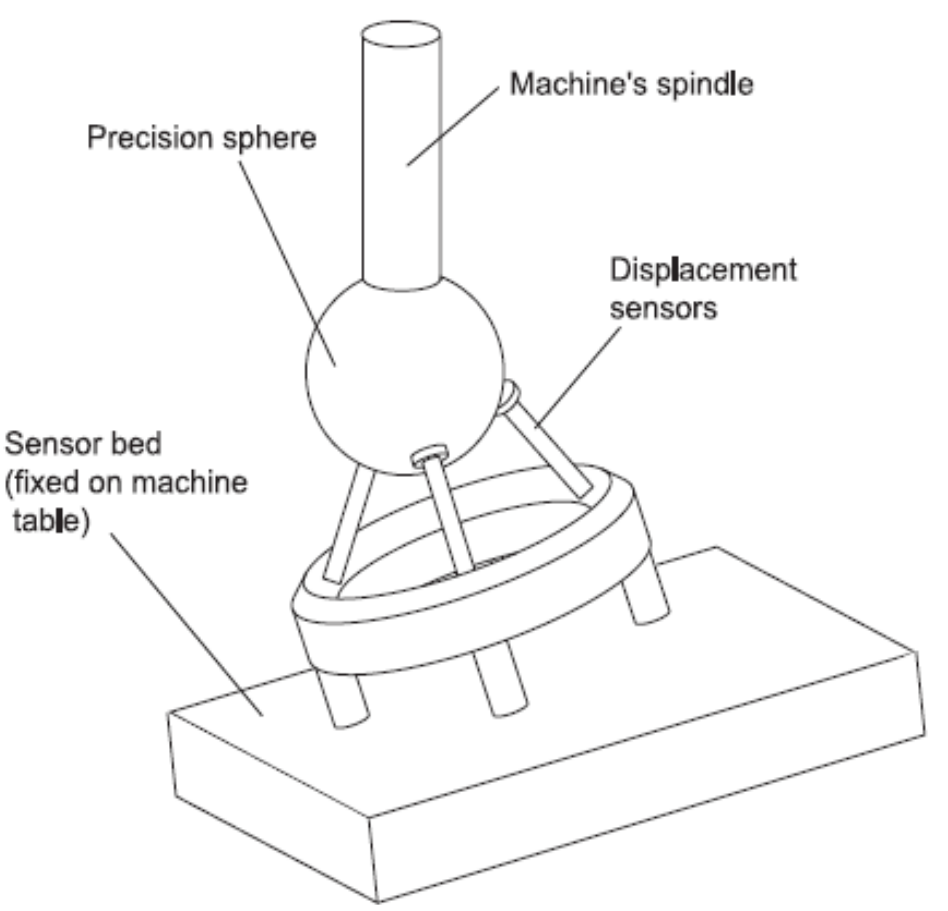

Fig. 5 R-test device [23].

The R-Test may be seen as an extension of the DBB test for measurement in three coordinates. The system consists of three or four analogs displacement sensors, positioned orthogonally relative to one another so that they are uniformly inclined in relation to the horizontal plane. Then a precision ball is positioned in contact with the sensors at the same time [22].

The sensors are mounted on a support that, where is mounted on the rotary table for measuring three-dimensional displacement of the precision ball which is mounted along the machine spindle [19].

The main idea of the measurement instrument is as follows: Using nominally flat contact geometries (diameter $12 \mathrm{~mm}$ ) between the probes and the sphere to be touched, the displacement of the center of the sphere is directly transfered to displacements of the three probes. The three measurement values directly lead to the 3-D-displacement of the sphere. It can be noted that these translation displacement are obtained also during rotational displacements of the sphere in contact [22].

Through this measurement device can calibrate errors like: backlash, positioning errors, flatness, parallelism, etc.

Comparing this device with the ballbar, the R-test has the advantage of obtaining the displacements in three dimensions for various rotation angles of the rotating axes simultaneously, without changes in configuration, as can be seen in Fig. 6 [19]. As disadvantages, have difficulty during the equipment mounting, such as the sphere and sensors, but also requires greater experience of the operator.

\subsection{Probing Artifacts}

In this type of calibration, the sensor has great communication with a system for numerical control (CNC), which potentially facilitates the automation of calibration errors and compensation [19].

The technique consists of a quasi-static test that can measure the inclination of the rotary axis probing multiple points using a device of rectangular geometry, or multiples artifacts, as shown in Fig. 7.

The advantages of artifacts from use in evaluating machines are related to the ease calibration with low uncertainty and speed in the tests. Use limitations are related to cleaning aspects, thermal stability and 

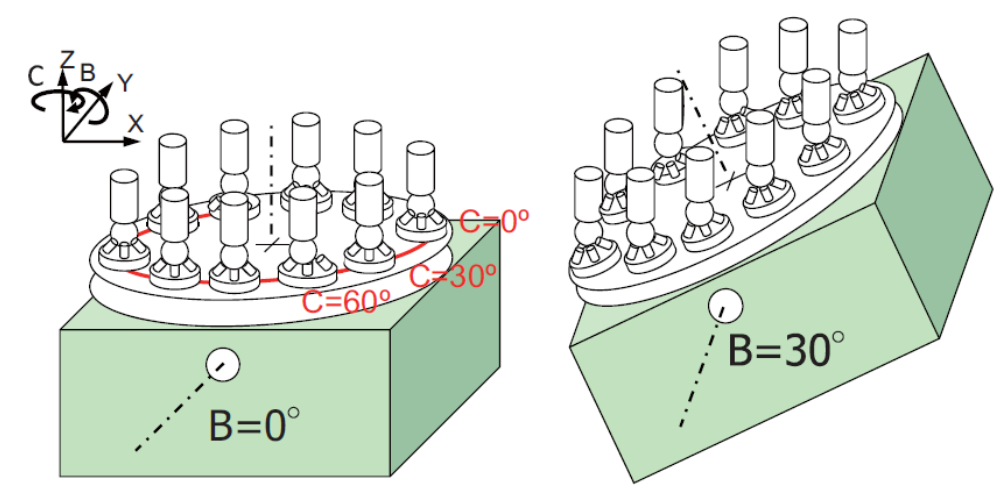

Fig. 6 Measurement with R-test device [19].

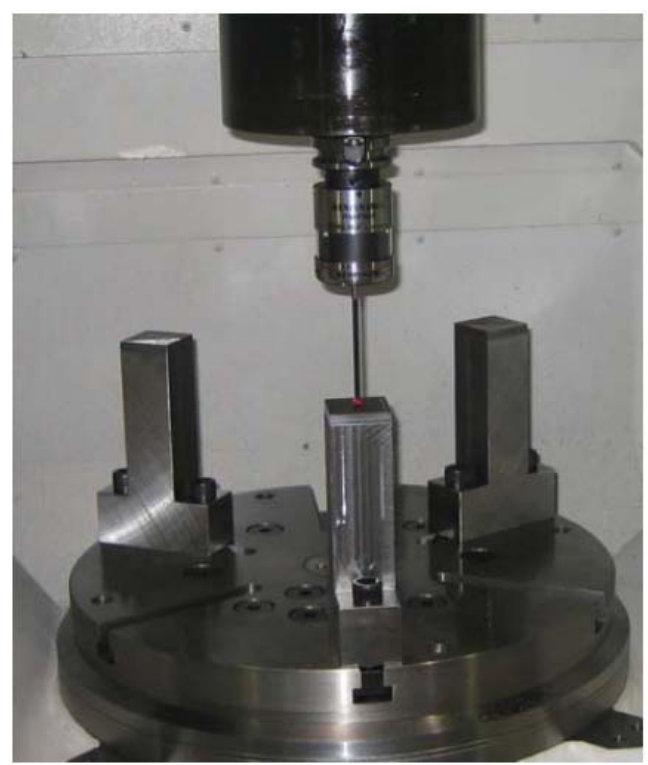

Fig. 7 Setup of three artifacts to calibrate translational and tilt error motions of rotary axes [19].

necessity of individual alignment of each block when the measurements [24].

\subsection{Tracking Interferometer}

The tracking interferometer, see Fig. 8, or the laser tracker, is a laser interferometer with a steering mechanism to change the laser beam direction to track a target retroreflector (typically a cat's eye). Three dimensional position measurement of the TCP can be done by conventional commercial laser trackers, by measuring the distance (displacement) to the target and the direction of the laser beam [19].

It is a method that potentially can be used for direct measurement of errors in a rotary tables arbitrary location without requiring synchronized motion of the linear axes [19].

The advantages associated with the use of laser tracker can be highlighted the low measurement uncertainty and ability to measure small displacements from up to tens of meters. It can also be used for measuring the geometric error components, such as perpendicularity, straightness, pitch and yaw [24].

As disadvantages are associated with the high cost of the equipment, the need for properly skilled operator, the high demand of time required in the tests. Regarding the results obtained, it is not possible to evaluate the machine in its entirety due to the assembly of the mobile reflector in the machine spindle. In operation, it presents difficulties in measuring straightness and perpendicularity errors.

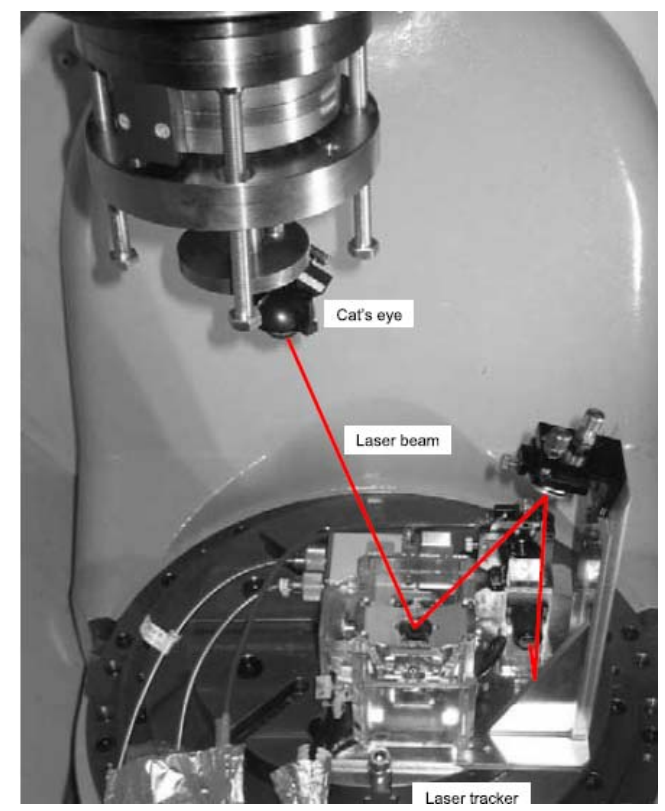

Fig. 8 Tracking Interferometer [19]. 


\section{Project and Development of an Aerostatic Rotary Table}

For this work, an aerostatic rotary table was developed, applied to CMM, where machining forces, present in machine tools, can be neglected, and the two rotational axis was based in a usual configuration in five axis machines, i.e., the $C$-axis realizes the rotate motion and is perpendicular to $A$-axis, that realize the tilt motion. This configuration allows that the device movements the workpiece at different set-up during the measurement.

Fig. 9 presents the project design developed, using the NX software, by Siemens ${ }^{\circledR}$.

The rotary table is composed for three parts:

Part 1: Is the machine structure. There, all other components of the system are mounted. The whole structure was designed using aluminum, besides being a material having the required strength, also has low specific weight;

Part 2: Are the aerostatic bearings. The bearings were designed to support the loads applied. The material chosen was the brass, metallic alloy consisting of copper and zinc, in the manufacture of parts. Four bearings were developed, being three radial bearings and one axial;

Part 3: The tables that compose each rotary table axis are shown. One of them is the tilt (A-axis) and the other one is the rotate ( $C$-axis). In coordinate measuring machine the workpiece to be measured will be fixed on the last one. The material used was aluminum, for the same reason it was chosen for the structure.

Fig. 10 below presents an exploded view of the prototype, where can see the assembly details of the components.

The aerostatic bearing installed has the function to separate two surfaces through by a thin layer by fluid, in this case the air that is compressed by a determinate value. The air inlet in a hole, and the flow's outlet occurs in various feed holes with small diameter, 0.5 $\mathrm{mm}$ approximately, uniformly distributed in the bearing, as shown in Fig. 11, creating a lubricating fluid layer separating the fixing part which comes into the movement, decreasing the friction in the regions of the parts are in motion.

The air consumption values and machine stiffness can be estimated theoretically. According the model presented by Venkatesh and Izman [25], the geometry of each bearing set type was used as the value for the feed pressure $5.0 \mathrm{bar}=505.75 \mathrm{kPa}$, and considering other parameters default values, such as clearance between the shaft and bore $0.0127 \mathrm{~mm}$; working temperature of $15{ }^{\circ} \mathrm{C}$ and pressure ratio of 0.4 . For these conditions, the radial bearing has a flow demand $0.841 \mathrm{l} / \mathrm{min}$ and rated stiffness on the order of

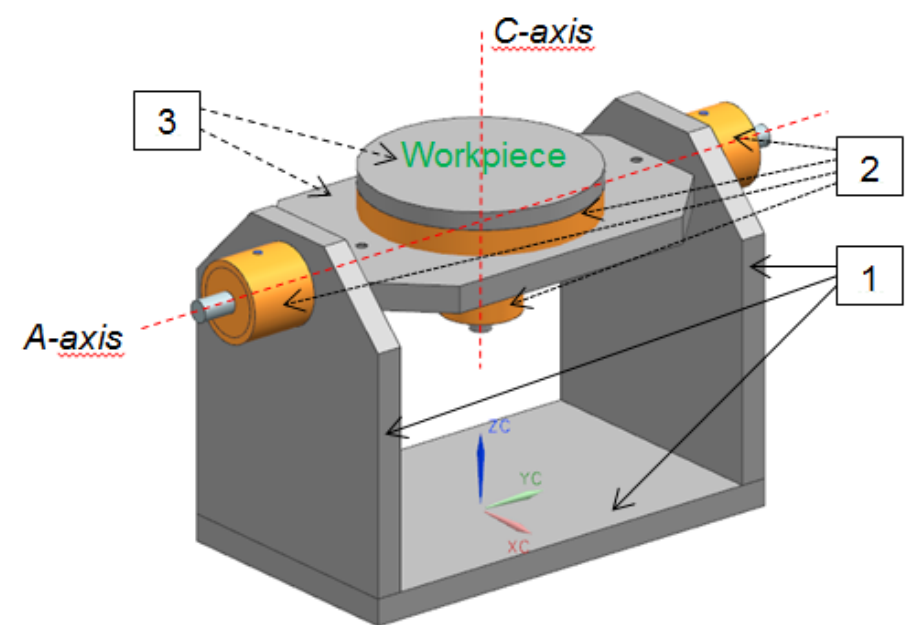

Fig. 9 General view of the rotary table designed: (1) machine structure; (2) aerostatic bearings; and (3) rotate and tilt tables. 


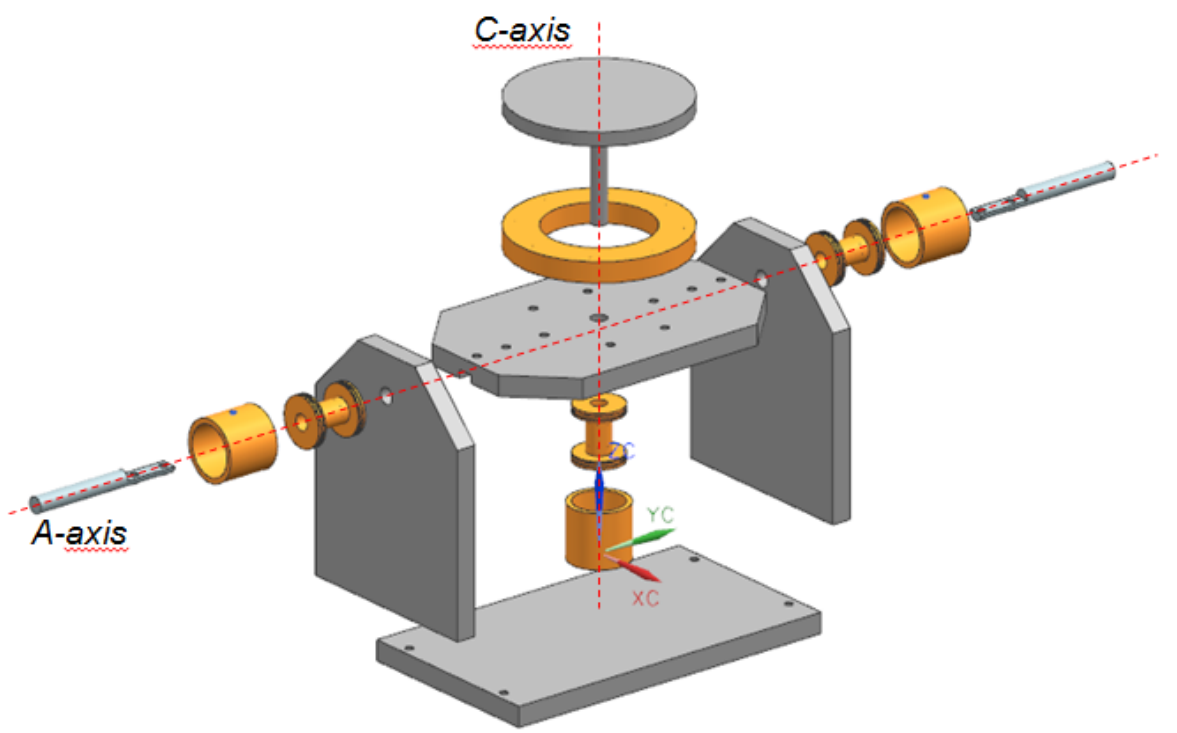

Fig. 10 Exploded view of the rotary table developed.

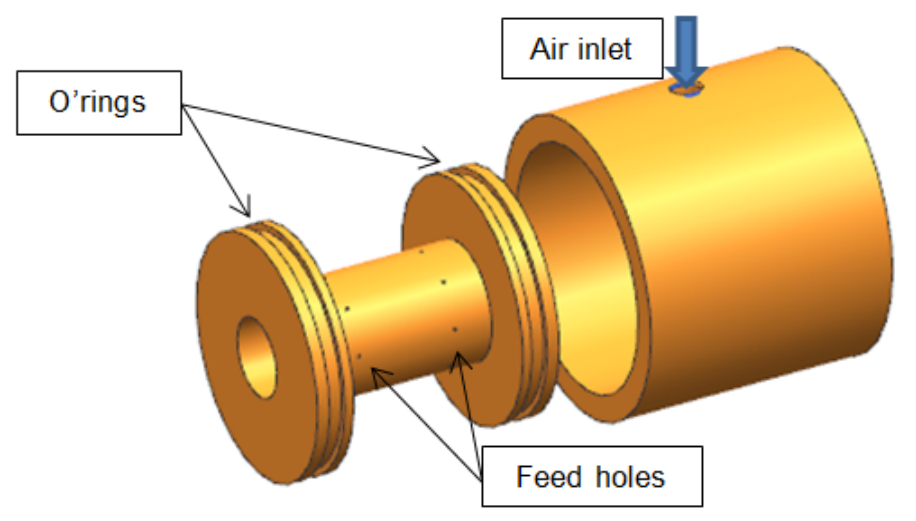

Fig. 11 Aerostatic bearing designed.

$4.60 \mathrm{kN} / \mathrm{mm}$. For the thrust bearing, the flow demand is around $15.65 \mathrm{l} / \mathrm{min}$, with estimated stiffness in $131.07 \mathrm{kN} / \mathrm{mm}$, after applied the appropriate corrections.

It can be concluded that the above estimate values for the air circuit attend sufficiently the operation demand. With respect to stiffness, the estimated values also attend the design requirements, ensuring the operation of the system to the experimental tests.

The parts that compose the rotary table were made by conventional machining methods, such as: milling, lathe, drilling, adjustment and polishing surfaces by sanding. Fig. 12 shows the mounting system, where you can observe the connections to the air system in each bearing.
Flexible couplings for motion transmission were mounted between the servo and the tables. The choice of this type of coupling ensures misalignment compensation because any small movements originated during the air supply in the bearings.

The air that will serve to feed the aerostatics bearings is captured from the external environment, through various processes which include a compression system, which is responsible for a compressor that raising the pressure of the air. A storage system, comprising to the reservoir connected to the compressor. A system of treatment that consists of passing the air through filters for removal the impurities and through a dryer, where it will be reduced to the maximum the humidity present in the air by a cooling system. Ending by a 

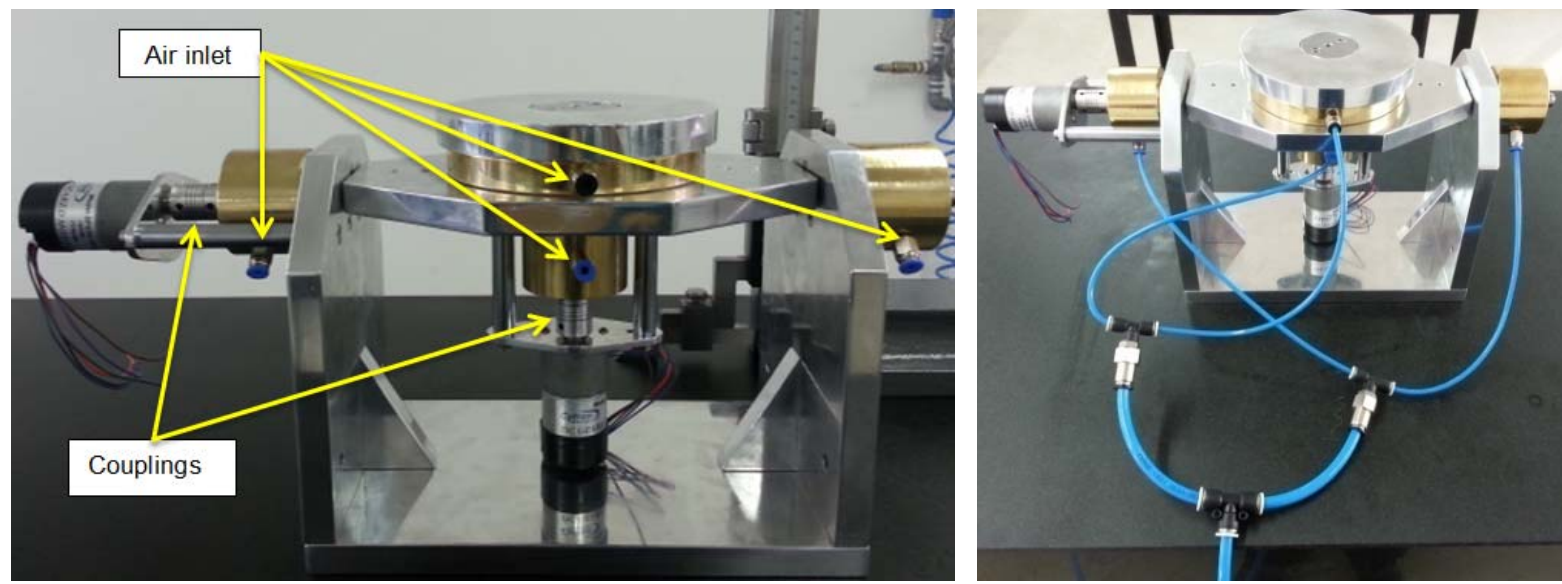

Fig. 12 Aerostatic rotary table developed.

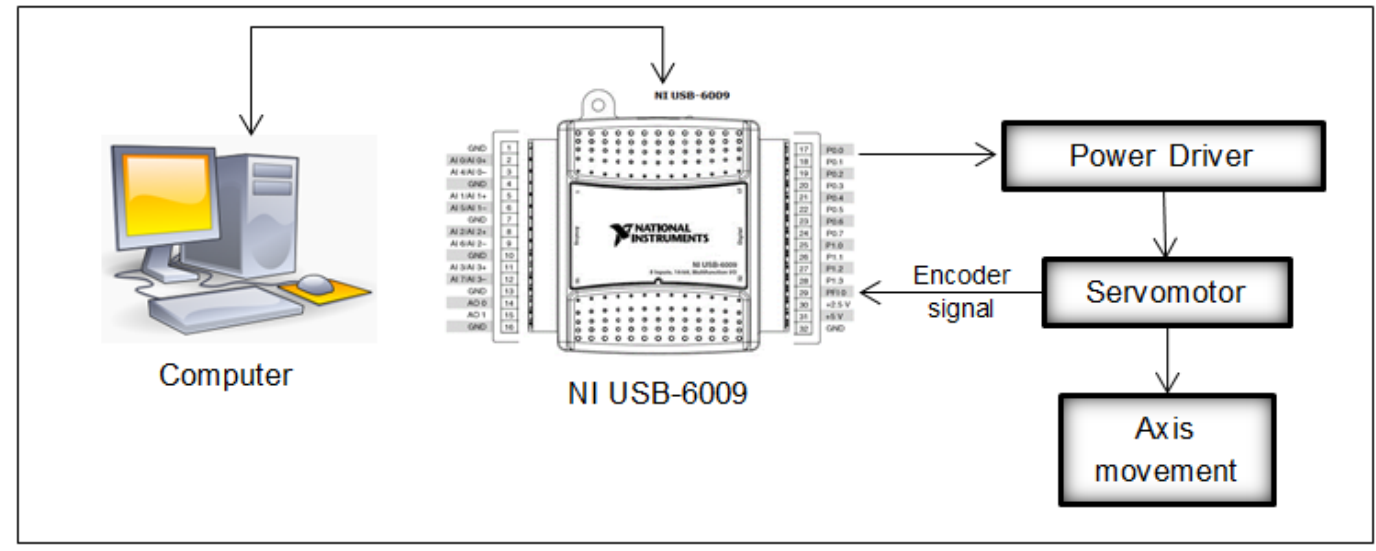

Fig. 13 Instrumentation realized for the rotary table.

pressure control valve and flow out with these parameters and controlled by a specific pipe according to reach the bearings.

After the development of the structural part of the rotary table, an instrumentation required for the movement of the axes has been developed for carrying out the experimental tests. Schematically, Fig. 13 shows all the components of this instrumentation, indicated by block diagram for data acquisition and drivers.

These components form a control system in open loop where the displacement performed by the table is determined by the number of pulses sent by the encoder that is coupled to the servomotor without the feedback loop.

For driving the servomotor, a data acquisition board from National Instruments ${ }^{\circledR}$ USB-6009 model was used. This board enables communication via USB port to a computer, through Labview ${ }^{\circledR}$ Software.

\section{Experimental Tests}

For realize the experimental tests, was used a DBB (Double Ballbar) system, model QC20-W by Renishaw ${ }^{\circledR}$. This equipment measures existing geometric errors through circular movements or arcs executed by the machine. Small deviations in the radius of this movement are measured by the transducer and sent through by software, where the results are displayed on the screen.

The DBB has the following specifications: maximum sample rate 1,000 samples/sec; nominal length of the transducer $100 \mathrm{~mm}$ (between the centers of the spheres); measuring range of $-1.0 \mathrm{a}+1.0 \mathrm{~mm}$; resolution $0.1 \mu \mathrm{m}$ and accuracy of $\pm 0.5 \mu \mathrm{m}\left(20{ }^{\circ} \mathrm{C}\right)$. 
If the machine had no errors, the graph would show perfect circle, and the radius is equal to the length of the measurement bar (transducer). The presence of any errors will distort this circle, by the addition of peaks along the circumference and possibly making it elliptical. These deviations reveal problems and inaccuracies in the numerical control, servo control system and the machine axes [22]. The errors measured by the DBB are overall motion errors, including position-dependent motion errors and tracking-speed-dependent motion errors [11].

The DBB system is usually used for measurements of circular motion of two linear axes, but in this research a specific adaptation was made to measure in rotational movement, using the instrument. To install the DBB in the machine, an adaptation was performed by installing a carbon steel flat bar of dimensions: 50 mm wide and $190 \mathrm{~mm}$ long in the upper surface of the rotary table ( $C$-axis), where was installed the moved part of the DBB. This adaptation ensures a length of $100 \mathrm{~mm}$, required distance between the centers of the measuring instrument precision ball. In parallel, was developed an aluminum structure, fixed on the tilt table (A-axis), where were installed the others components, the fixed parts of the DBB system, as shown in Fig. 14.

This structure allows that the measuring system can be fixed in the tilt table during further tests for different angles of the tilt table. During the tests, between the fixed part and the moved part is installed the DBB transducer, responsible to capture the movement signals. The measuring ball which is mounted on the structure remains stationary while that the measuring ball mounted on the table moves along a circular path formed in accordance with the tilt and rotational axis of movement settings. The captured data are synchronized with the circular motion by trigger signals, and these signals are sent to the computer via bluetooth.

Settings were implemented in the equipment in the following manner: the tilt axis was positioned in the horizontal position $\left(0^{\circ}\right)$, adjusted with a level meter. Then, the rotational axis is moved $720^{\circ}$ in the CCW (counter-clockwise) direction followed of a movement of $720^{\circ}$ clockwise (CW) direction. The DBB moves in $\mathrm{CCW}$ or $\mathrm{CW}$ in data capture arches of $360^{\circ}$ with $180^{\circ}$ of overshoot arc, where this one is the arc traveled by the Ballbar transducer before and after data capture arc.

The Renishaw analysis software can analyze the captured data accord to international standards, among which we can highlight the ISO 230-4 standard, which specifies test methods and evaluates the circular hysteresis, circular deviation of the circular tests that

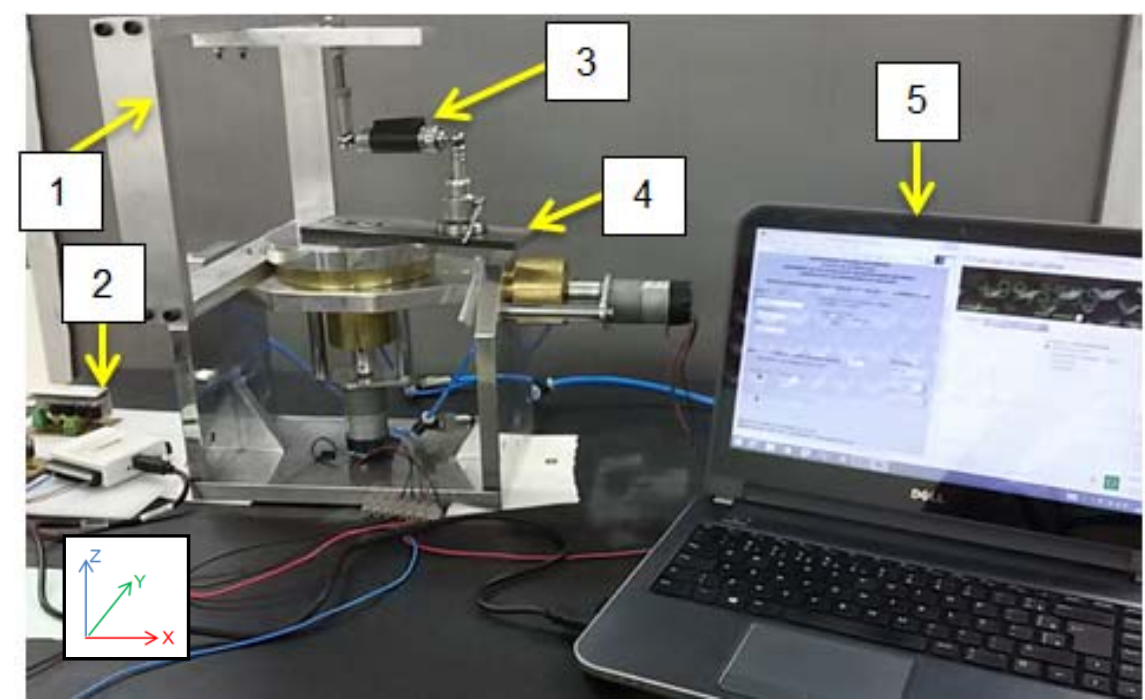

Fig. 14 Experimental tests in the system: (1) aluminum structure; (2) power drive and control system; (3) DBB transducer; (4) flat bar; and (5) computer. 
are produced by the simultaneous movement of two linear axes, which can be applied to the objectives of this work. Automatically, the software diagnoses the machine errors and evaluates the performance of a machine.

The software displays reports on the ISO 230-4 standard: 2005 , which are available the views: two circular deviations (one clockwise and the other counterclockwise) and the circularity. The circular hysteresis can also be viewed by accessing the ISO 230-4 standard: 1996, on the software result screen.

The circular deviations $(G)$ are the maximum deviations around a circle. They are individually performed on the $\mathrm{CW}$ (clockwise) and $\mathrm{CCW}$ (counterclockwise) directions, adjusted individually to remove any difference of center relative to the center of the circle that best passes through the captured data [19]. According to Fig. 1, these errors can be associated to the radial or eccentricity errors ( $\Delta \mathrm{x}$ and $\Delta y)$.

The circular hysteresis $(H)$ is the maximum radial separation between data captured by a clockwise moving and the other by in a counterclockwise direction.

And the circularity value represents the difference between the lowest and the highest radius registered by the Ballbar during the data capturing arches movement.

\section{Results}

The following graphs show the results obtained using the DBB, which were observed system behavior by varying the feedrate $(f)$, parameter considered of great influence on the results of the geometric errors.

The tests allow the visualization of geometric errors dynamically, i.e., with the rotary table moving during the tests, carried out for just a work plan, the XY plane, and an angle of $0^{\circ}$ in tilt axis.

Fig. 15 presents the first results obtained from the use of the DBB. This result was obtained in accordance with the described set-up, which resulted in a feedrate of $5,900 \mathrm{~mm} / \mathrm{min}$. The measurement errors were carried out with bearings supplied at a feed pressure of 5.0 bar.

Based on Fig. 15, the software also presents the following results: circular deviation of $929.7 \mu \mathrm{m}$ in $\mathrm{CW}$ direction and $794.4 \mu \mathrm{m}$ in $\mathrm{CCW}$ direction, circularity of $1,248.4 \mu \mathrm{m}$ and circular hysteresis of $1,108.5 \mu \mathrm{m}$, located at $140.86^{\circ}$ position.

Analyzing the data, it was observed that the results found are with high values which may be caused mainly by both the elapsed clearances in the aerostatic

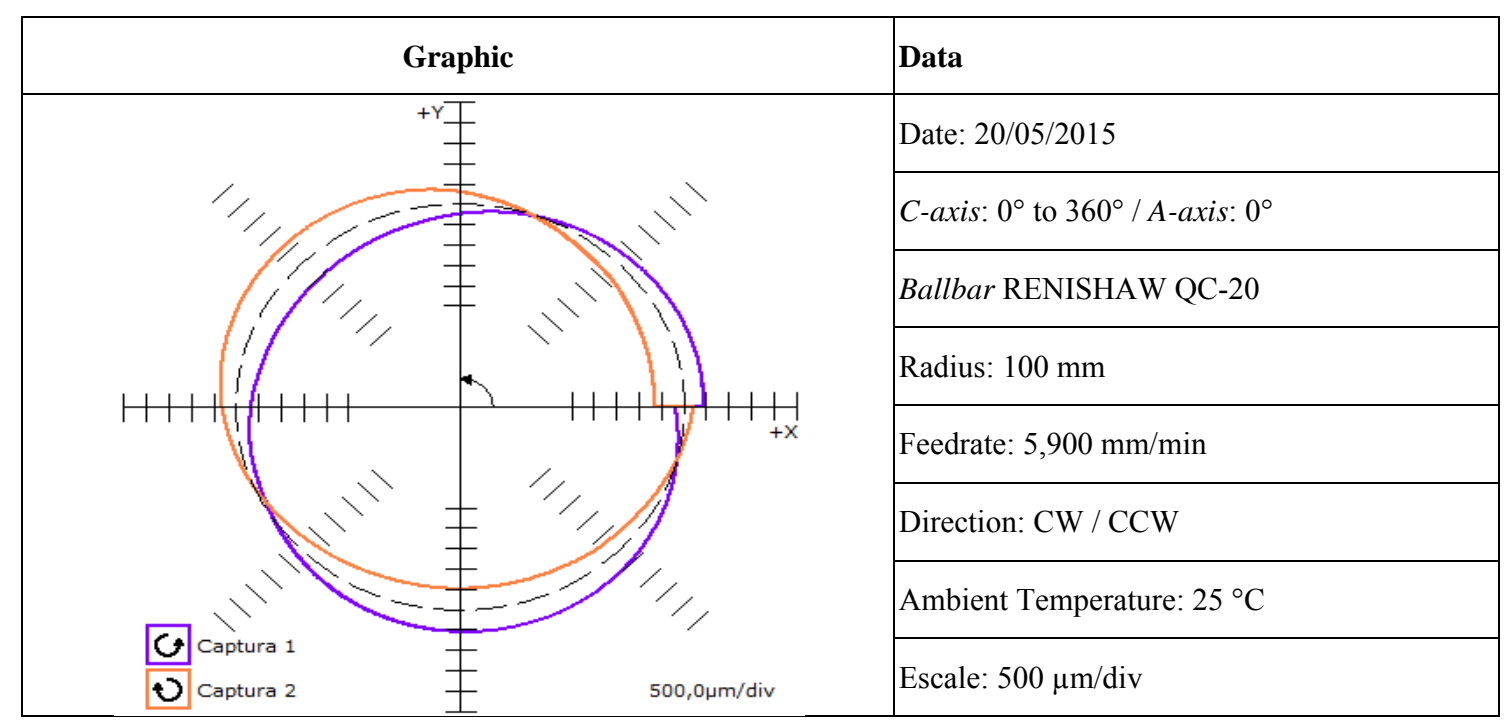

Fig. 15 Results with $f=5,900 \mathrm{~mm} / \mathrm{min}$. 
bearings during the mounting system, as the high feedrate employed during the tests, that not is a common value when performing tests with high accuracy machines.

So the next step was to develop system changes that were able to reduce the geometrical errors caused previously, to obtain specific conclusions about the use of aerostatic bearings in rotary tables.

To decrease the feedrate in the system, changes were carried out in the servomotor power supply that drives the $\mathrm{C}$-axis. The servomotor that was been powered with $12 \mathrm{~V}$ and becomes engaged with the values $7.5 \mathrm{~V}, 6.0 \mathrm{~V}$ and $5.0 \mathrm{~V}$, thereby obtaining new feedrate of approximately: $3,200 \mathrm{~mm} / \mathrm{min}, 2,500$ $\mathrm{mm} / \mathrm{min}$ and $1,800 \mathrm{~mm} / \mathrm{min}$, respectively.

After the above modifications, new tests were performed following the same procedure data capture. Fig. 16 shows the results with the system operating with feedrate of $3,200 \mathrm{~mm} / \mathrm{min}$.

Fig. 17 shows the results for the feedrate of 2,500 $\mathrm{mm} / \mathrm{min}$, performed in the same conditions previously.

\begin{tabular}{|c|c|}
\hline Graphic & Data \\
\hline \multirow{8}{*}{$\begin{array}{c}\text { Captura 1 } \\
\Theta \text { Captura 2 }\end{array}$} & Date: $02 / 07 / 2015$ \\
\hline & C-axis: $0^{\circ}$ to $360^{\circ} / A$-axis: $0^{\circ}$ \\
\hline & Ballbar RENISHAW QC-20 \\
\hline & Radius: $100 \mathrm{~mm}$ \\
\hline & Feedrate: $3,200 \mathrm{~mm} / \mathrm{min}$ \\
\hline & Direction: CW / CCW \\
\hline & Ambient Temperature: $25^{\circ} \mathrm{C}$ \\
\hline & Escale: $500 \mu \mathrm{m} / \mathrm{div}$ \\
\hline
\end{tabular}

Fig. 16 Results with $f=3,200 \mathrm{~mm} / \mathrm{min}$.

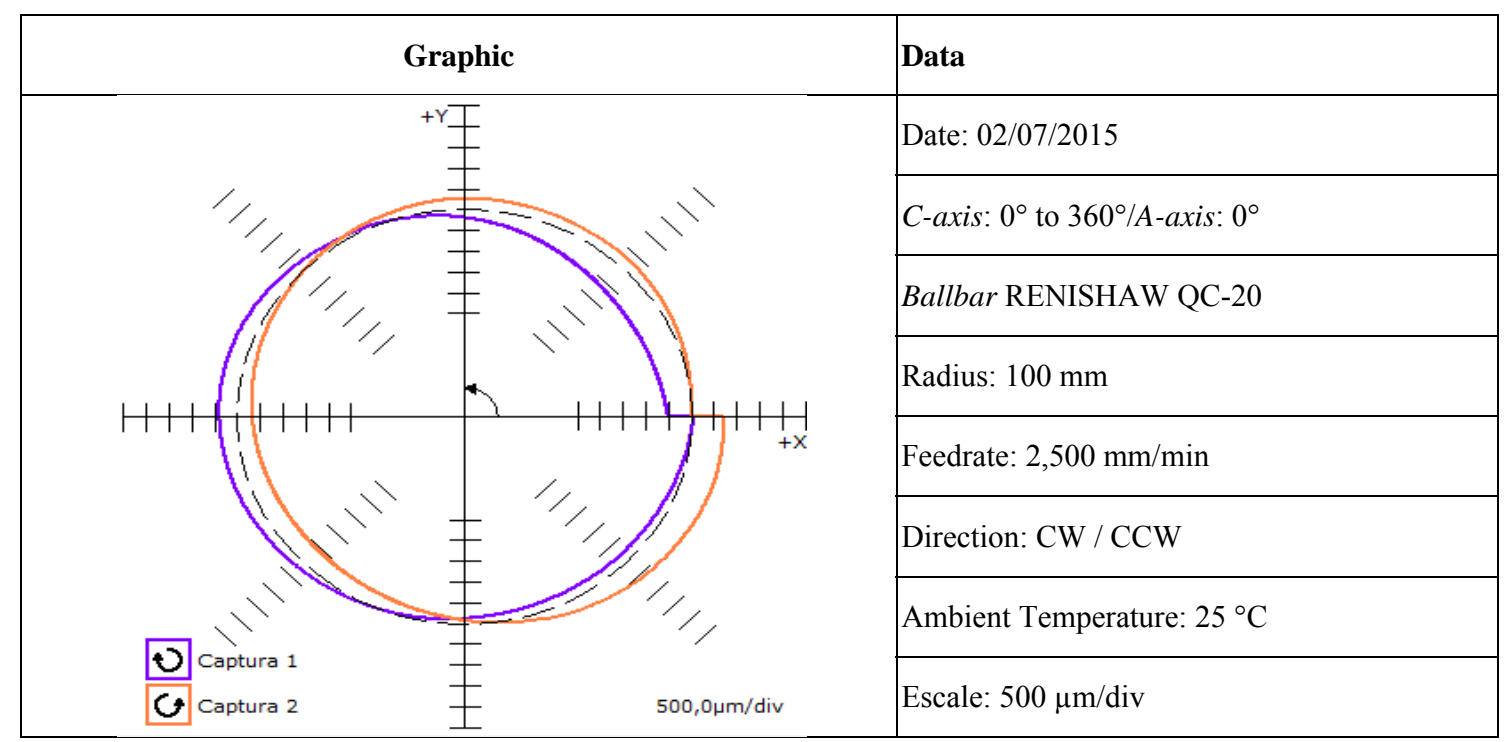

Fig. 17 Results with $f=2,500 \mathrm{~mm} / \mathrm{min}$. 


\begin{tabular}{|c|c|}
\hline Graphic & Data \\
\hline \multirow{7}{*}{$H+H$} & Date: $02 / 07 / 2015$ \\
\hline & $C$-axis: $0^{\circ}$ to $360^{\circ} / A$-axis: $0^{\circ}$ \\
\hline & Ballbar RENISHAW QC-20 \\
\hline & Radius: $100 \mathrm{~mm}$ \\
\hline & Feedrate: $1,800 \mathrm{~mm} / \mathrm{min}$ \\
\hline & Direction: $\mathrm{CW} / \mathrm{CCW}$ \\
\hline & Ambient Temperature: $25^{\circ} \mathrm{C}$ \\
\hline G Captura 2 & Escale: $500 \mu \mathrm{m} / \mathrm{div}$ \\
\hline
\end{tabular}

Fig. 18 Results with $f=1,800 \mathrm{~mm} / \mathrm{min}$.

Table 1 Results varying the feedrate.

\begin{tabular}{|l|l|l|l|}
\hline & \multicolumn{3}{|c|}{ Feedrate } \\
\hline Parameters & $3,200 \mathrm{~mm} / \mathrm{min}$ & $2,500 \mathrm{~mm} / \mathrm{min}$ & $1,800 \mathrm{~mm} / \mathrm{min}$ \\
\hline$G(C W)$ & $1,076.9$ & 753.0 & 557.2 \\
\hline$G(C C W)$ & 880.3 & 779.6 & 479.8 \\
\hline$H$ & $1,361.9$ & 815.3 & 742.7 \\
$\left(321.09^{\circ}\right)$ & $\left(47.37^{\circ}\right)$ & $1,117.8$ \\
\hline Circularity & $1,432.8$ & $1,417.9$ & \\
\hline
\end{tabular}

Legend: G- circular deviation; H- circular hysteresis; CW- clockwise; CCW- counterclockwise.

Values in $\mu \mathrm{m}$

And in Fig. 18 are the results obtained for the feedrate of $1800 \mathrm{~mm} / \mathrm{min}$.

And based on the graphic showed previously, the circular deviation, circular hysteresis and circularity were organized and presented on the Table 1 below.

The results presented above were notable reductions possible in the values of the observed parameters, such as circularity, circular deviation and the hysteresis, when was reduced the feedrate. Although, several research papers used as a default value in their presentation of experimental tests, results with feedrate around $500 \mathrm{~mm} / \mathrm{min}$.

In this prototype, the circular deviations represent the clearance on the air bearings, causing unwanted movement in the machine axes.

\section{Conclusions}

The application of the DBB method to inspect the motion errors of an aerostatic rotary table has been investigated. The measuring method was applied in a prototype of rotary table which uses air bearings to reduce the friction among the moving parts. This methodology allows the geometric error identification of rotary tables in practical and fast way compared to the other methods such as interferometer laser and auto-collimator.

These experimental results allow observing the behavior of the developed prototype, by identifying the points that shall be improved in the system. Therefore, further experimental work will be developed in order to improve the design of the developed rotary table and its performance, such as improve the aerostatic bearings design, offering on the rotational table feeding orifices in the radial direction. In addition, experimental tests with different $A$-axis angles will be developed. 
The error measurement methodology of rotary tables using the DBB system, presented in this paper, proved to be an important tool for measuring their geometric errors such as: circular deviation, circular hysteresis and circularity. Additionally, it contributes to minimize these errors still in an early design stage and thus obtain an improvement in the rotary table accuracy, e.g., through to the reduction of the clearance in the air bearings, in particular those applied in Coordinate Measuring Machines.

\section{Acknowledgements}

The authors would like to thank the Federal University of Paraíba (UFPB), Post Graduate Program in Mechanical Engineering (PPGEM) for financial and scientific support for this research.

\section{References}

[1] Porto, A. J. V. 2004. Usinagem de ultraprecisão, FAPESP, São Carlos, Brazil.

[2] Ibaraki, S., Iritani, T., and Matsushita, T. 2012. "Calibration of Location Errors of Rotary Axes on Five-Axis Machine Tools by on-the- Machine Measurement Using a Touch-Trigger Probe." International Journal of Machine Tools \& Manufacture 58: 44-53.

[3] Wang, W., Zhang, Y., and Yang, J. 2013. "Double Ballbar Measurement for Identifying Kinematic Errors of Rotary Axes on Five-Axis Machine Tools." Advances in Mechanical Engineering 2013 (2013): 1-8.

[4] Nóbrega, L. H. M. S. 2011. "Projeto e desenvolvimento de um apalpador touch trigger de baixo custo para medição por coordenadas.” Federal University of Paraíba, João Pessoa, Paraíba, Brazil. (In Portuguese)

[5] Balestrero, L. A. P. and Purquerio, B. M. 1999. "Avaliação de mancais aerostáticos para eixos-árvore." Machinery and Metals XXXVI. (In Portuguese)

[6] Freitas, D. S. and Prata, A. T. 1995. "Simulação Numérica de Mancais aerostáticos esféricos." Revista Internacional de Métodos Numéricos para Cálculo y Diseño em Ingeniería 11 (1995): 543-553. (In Portuguese)

[7] Khan, A. W., and Chen, W. 2010. "A Methodology for Error Characterization and Quatification in Rotary Joints of Multi-axis Machine Tools." International Journal of Advanced Manufacturing Technology 51: 1009-22.

[8] Zhu, S., Ding, G., Qin, S., Lei, J., Zhuang, L., and Yan, K.
2012. "Integrated Geometric Error Modeling, Identification and Compensation of CNC Machine Tools." International Journal of Machine Tools \& Manufacture 52: $24-9$.

[9] Lee, K., and Yang, S. 2013. "Accuracy Evaluation of Machine Tools by Modeling Spherical Deviation Based on Double Ball-Bar Measurements." International Journal of Machine Tools \& Manufacture 75: 46-54.

[10] Lee, K., and Yang, S. 2013. "Measurement and Verification of Position-Independent Geometric Errors of a Five Machine Tool Using a Double Ball-Bar." International Journal of Machine Tools \& Manufacture 70: 45-52.

[11] Lei, W. T., Sung, M. P., Liu, W. L., and Chuang, Y. C. 2007. "Double Ballbar Test for the Rotary Axes of Five-Axis CNC Machine Tools." International Journal of Machine Tools \& Manufacture 45: 273-85.

[12] Tsutsumi, M., Tone, S., Kato, N., and Sato, R. 2013. "Enhancement of Geometric Accuracy of Five-Axis Machining Centers Based on Identification and Compensation of Geometric Deviations." International Journal of Machine Tools \& Manufacture 68: 11-20.

[13] Zhang, Y., Yang, J., and Zhang, K. 2013. "Geometric Error Measurement and Compensation for a Rotary Table of Five-Axis Machine Tool with Double Ballbar." International Journal of Advanced Manufacturing Technology 65: 275-81.

[14] Chen, J., Lin, S., and He, B. 2014. "Geometric Error Measurement and Identification for Rotary Table of Multi-axis Machine Tool Using Double Ball-Bar." International Journal of Machine Tools \& Manufacture 77: 47-55.

[15] Srivastava, A. K., Veldhuis, S. C., and Elbestawit, M. A. 1995. "Modelling Geometric and Thermal Errors in a Five-Axis CNC Machine Tool." International Journal of Machine Tools \& Manufacture 35: 1321-37.

[16] Jywe, W., Chen, C. J., Hsieh, W. H., Lin, P. D., Jwo, H. H., and Yang, T. Y. 2007. "A Novel Simple and Low Cost 4 Degree of Freedom Angular Indexing Calibrating Technique for a Precision Rotary Table." International Journal of Machine Tools \& Manufacture 47: 1978-87.

[17] Silva, J. B. A., Hocken, R. J., Miller, J. A., Caskey, G. W., and Ramu, P. 2009. "Approach for Uncertainty Analysis and Error Evaluation of Four-Axis Co-ordinate Measuring Machines.” International Journal Advanced Manufacturing Technology 41: 1130-9.

[18] Slocum, A. 1992. Precision Machine Design. New Jersey: Prentice Hall.

[19] Ibaraki, S., and Knapp, W. 2011. "Indirect Measurement of Volumetric Accuracy for Three-Axis and Five-Axis Machine Tools: A Review." International Journal of Automation Technology 6: 110-24. 
[20] Lee, K., and Yang, S. 2013. "Measurement and Verification of Position-Independent Geometric Errors of a Five Machine Tool Using a Double Ball-Bar." International Journal of Machine Tools \& Manufacture 70: 45-52.

[21] RENISHAW [Online]. http://www.renishaw.com/en/. Access in: 09 may 2014.

[22] Weikert, S., and Knapp, W. 2004. "R-Test, a New Device for Accuracy Measurements on Five Axis Machine Tools." Annals of CIRP 53 (1): 429-32.
[23] Ibaraki, S., Oyama, C., and Otsubo, H. 2011. "Construction of an Error Map of Rotary Axes on a Five-Axis Machining Center by Static R-test.” International Journal of Machine Tools \& Manufacture 51: 190-200.

[24] Rolim, T. L. 2003. "Sistemática indicadora de método para calibração de máquinas de medição por coordenadas.” Federal University of Paraíba, João Pessoa, Paraíba, Brazil. (In Portuguese)

[25] Venkatesh, V. C., and Izman, S. 2007. Precision Engineering. New Delphi: McGraw-Hill. 